\title{
Plants and plant extracts for improving animal productivity
}

\author{
Henry Greathead \\ School of Biology, University of Leeds, Leeds LS2 9JT, UK
}

\begin{abstract}
Plant secondary metabolites are a natural resource that is largely unexploited in 'conventional' animal production systems. They have in the past been generally considered as a source of antinutritional factors, and not as a source of exploitable performance-enhancing compounds. Recent and continuing changes to legislation controlling the use of animal feed additives have stimulated interest in bioactive secondary metabolites as alternative performance enhancers. They are broadly compatible with current thinking on the future of agriculture and food in Europe, and with consumer opinion. Interest has been largely on their manipulative role in the digestive and absorptive processes of the hindgut. The present paper will review the use of plants and their extracts to manipulate the rumen microbial ecosystem to improve the efficiency of rumen metabolism. The bioavailability of secondary metabolites and their actions on peripheral metabolism will be considered with a view to improving animal performance. The challenge of delivering plants and their extracts to animals outdoors in a controlled manner will be discussed. Much of what is known about the beneficial roles of plant secondary metabolites on animal performance is circumstantial and is based on tenuous data. In order to more fully exploit their bioactive properties for the benefit of animal performance, modes of action need to be understood. Uptake will be dependent on proven efficacy and consumer acceptance of assurances relating to safety, welfare and the environment.
\end{abstract}

\section{Plant secondary metabolites: Essential oils: Rumen: Metabolism: Delivery system}

Plants in the context of animal production are thought of first and foremost as the principal source of nutrients for animals, and sometimes as an unwelcome source of anti-nutritional factors that interfere with an animal's ability to maximise utilisation of ingested nutrients. Until fairly recently, mainstream animal production in the West had not seriously considered plants as a source of non-nutrient performanceenhancing factors that could be exploited to benefit animal productivity. Those individuals that did were often considered 'quacks', reflecting the prejudices of Western societies in which traditional, often plant-based, treatments have been regarded with scepticism, despite the fact that $80 \%$ of the world's population rely on traditional treatments (Farnsworth et al. 1985), and 25\% of the prescriptions dispensed by pharmacies contain extracts or active principles derived from higher plants (Newman et al. 2000). However, mainstream attitudes are changing, and over the last 5-8 years there has been a surge of interest in the use of plants and their extracts as alternative performance enhancers for animals.

The number of papers being published on the use of the non-nutrient factors in plants and their extracts to improve animal performance has increased. However, the majority of these papers are reports on production ('feed and weigh' type) experiments, with very little information detailing structure-function relationships and mechanisms of action. This highlights the current 'product-driven' approach to the development of performance-enhancing plant extracts, rather than perhaps the more desirable and universal science-based 'function-driven' approach (Roberfroid, 1999).

The present review considers the background to the recent surge of interest in the use of plants and their extracts as alternative performance enhancers, and the non-nutrient bioactive compounds of plants, the secondary metabolites. Possible ways of manipulating rumen and peripheral metabolism via the use of plant secondary metabolites are discussed in relation to what is currently known about the bioactive roles of these compounds.

\section{Background to the current interest in the use of plants and their extracts as alternative performance enhancers}

The use of plants and their extracts in animal production is not new. Ethno-veterinary practices developed alongside 
those of ethno-medical practices. The first records of plantbased traditional medicine systems date back to about 2600 $\mathrm{BC}$ and are from Mesopotamia (Newman et al. 2000). Traditional medicine systems were widely used in the West up until the mid 20th century, at which time they were superseded by synthetic drugs, which were novel, effective and could be easily patented, thus assuring profitability (Tyler, 1999). For example, before the advent of readilyavailable antibiotics in the $1950 \mathrm{~s}$, antimicrobial plant derivatives were commonly used (Cowan, 1999). Research from the 1950 s to the 1980 s concentrated very much on the plant nutrients (Cragg et al. 1997). From the late 1980s to the late 1990s there was a resurgence of interest by pharmaceutical companies in plants as potential sources of new chemotherapeutic agents. However, due to the difficulties (time and cost) associated with isolating and characterising the active principle(s) in the often complex extracts obtained from plant sources, interest has since declined in favour of new approaches to drug discovery (Shu, 1998; Cordell, 2000). This decline in interest by the pharmaceutical industries has coincided with increasing interest from the animal industry in the use of plants and their extracts as alternative performance enhancers for animals, particularly in the EU.

The single most important factor contributing to the animal industry's surge of interest in the use of plants as alternative performance enhancers has been the increasing legislation surrounding the use of the so-called medicinal feed additives market in the EU. This market can be segmented into antibiotics (e.g. oxytetracycline), antibacterials (e.g. carbadox), anticoccidials (e.g. salinomycin), growth promotants (e.g. monensin) and a group of 'others', which includes primarily anthelmintics (e.g. ivermectin). Since 1990 EU Directives and Regulations affecting the medicinal feed additives market have substantially increased. By 1998 all but four of the in-feed antibiotic growth promoters had been banned, i.e. tylosin phosphate, virginiamycin, bacitran zinc, spiramycin, carbadox and olaquinadox (Evans et al. 1999). New EC proposals are calling for a ban on the remaining four (monensin, avilamycin, flavophospholipidol and salinomycin) by January 2006. Warning shots have also been fired in the USA. Last year the American Medical Association passed a resolution to ' $\ldots$ oppose the use of antimicrobials at nontherapeutic levels in agriculture ...' (Lawrence \& Hahn, 2001).

There are two principal reasons behind the changes in legislation on the use of in-feed antibiotic growth promoters. The first is to try to combat the development of microbial resistance to antibiotic drugs and the consequences to human health. The second is a response to consumer pressures to eliminate the use of all non-plant xenobiotic agents from the diets of animals. Consumer pressures are founded on a belief that chemical residues, e.g. pesticides, growth hormones, antibiotic drugs and heavy metals, are the major threats to their health, despite the fact that without doubt the most predominant hazards in food are of microbial origin (Saucier, 1999).

If it is considered that: (1) in pigs the improvements in performance attributed to the use antibiotic growth promoters include, on average, $4 \%$ increases in gain and $2 \%$ increases in feed conversion efficiency; (2) over the last 30 years between 50 and $90 \%$ of all pig feeds contained antibiotic growth promoters (Lawrence \& Hahn, 2001); (3) the global market for antibiotic growth promoters was valued at US $\$ 237 \times 10^{6}$ at its peak in 1996 (Evans et al. 1999); then it is not difficult to appreciate the implications of the ban on the use of antibiotic growth promoters to the animal industry and industries allied to it. It is against this background of events that interest in alternative performance enhancers, which include plants and their extracts, has surged.

As alternatives, plants and their extracts are attractive, as they are broadly compatible with current thinking on the future of agriculture and food in the EU, and with consumer opinion that most things 'natural' are good. The market for plant-based performance enhancers has increased rapidly since the 1990s, coinciding with the demise of antibiotic growth promoters.

A good example of the growth in this market is that for essential oil products in the EU (Fig. 1). In 1996 the market was valued at $90 \mathrm{t}$ with revenues of $413000 €$ (Frost \& Sullivan, 2000). Since 1996 the market has experienced rapid growth, and in 2006 the forecast for the market is $601 \mathrm{t}$ with revenues of $1643000 €$.

\section{Plant secondary metabolites}

The non-nutrient bioactive principles in plants are essentially the secondary metabolites. Plant secondary metabolites differ from the ubiquitous primary metabolites (e.g. carbohydrates, proteins, fats, nucleic acids) in that their distribution is limited, often only being produced by specific plants or groups of plants. Even within individual populations and within individual plants themselves secondary metabolites vary quantitatively and qualitatively. An appreciation of this variability is essential when trying to interpret studies using non-characterised (chemically and biologically) plants and extracts (Marriott, 2000).

Whereas it was once believed that secondary metabolites served no function in the plant (Edwards \& Gatehouse, 1999), it is now generally accepted that secondary metabolites are an important means by which plants interact with their environments. They serve to protect plants from pathogens, herbivores, inter-plant competition and abiotic stresses, e.g. desiccation and u.v. radiation (Briskin, 2000). They also serve to attract beneficial organisms such as pollinators. Defensive secondary metabolites are often synthesised in response to a stressor. For example, repeat cutting of lucerne (Medicago sativa) has been shown to increase its saponin content (Marriott, 2000), and in some African grasses silicification increases in response to grazing pressure (McNaughton et al. 1985). Such secondary metabolites are termed 'induced' secondary compounds, as opposed to those secondary metabolites more normally present in plants in appreciable quantities, which are termed 'constitutive' secondary compounds (Marriott, 2000). Other theories of plant secondary metabolite function suggest that their protective roles are accidental, and that secondary metabolism serves to maintain primary metabolism in circumstances when the normal substrates of primary metabolism cannot be exploited for normal cellular growth and replication, i.e. that secondary metabolites are formed as a result of 'overspill' from primary metabolism (Gottlieb, 1990). Both theories can account for 


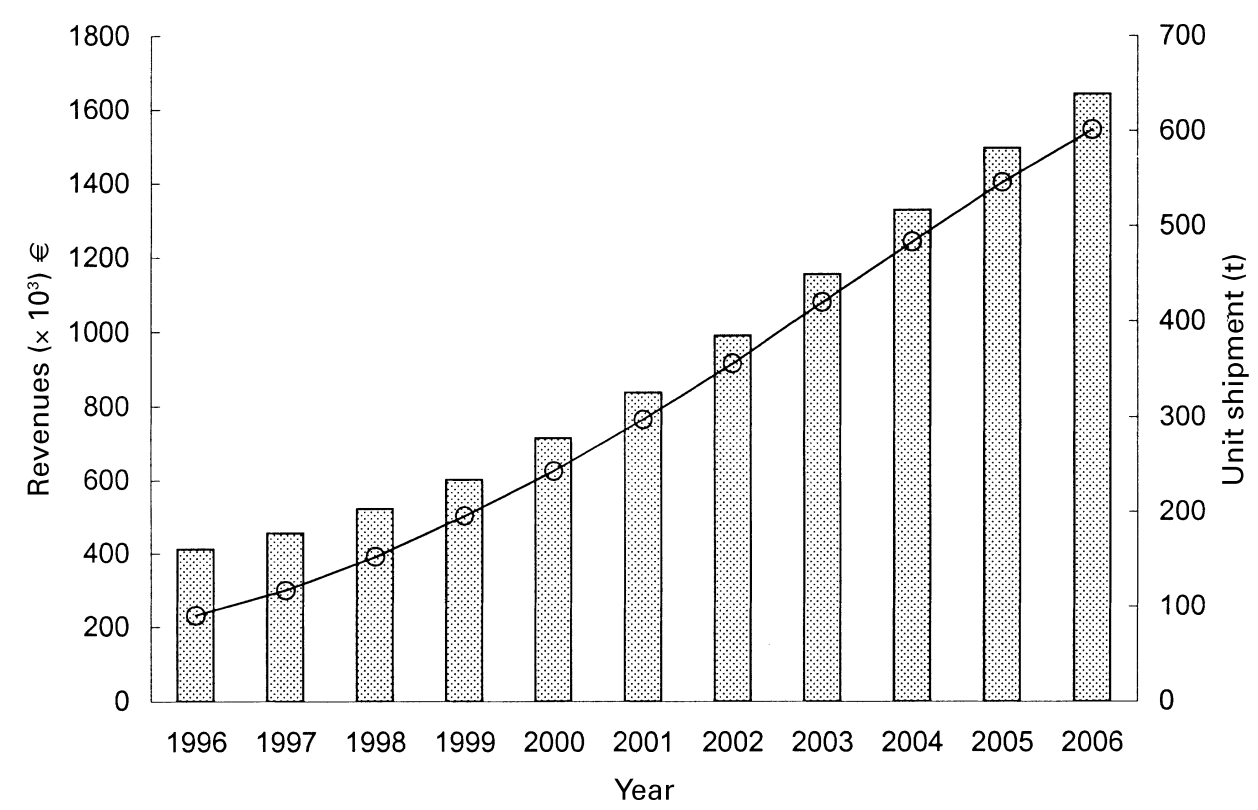

Fig. 1. Total EU market and forecasts for essential oils as feed additives: unit shipment $(\mathrm{O}-\mathrm{O})$ and revenue $(\square)$. (Adapted from Frost \& Sullivan, 2000.)

the quantitative and qualitative variability in the secondary metabolite content of plants.

The building blocks of secondary metabolites are derived from primary metabolism and are effectively tapped off from the processes of photosynthesis, glycolysis and the citric acid cycle (Fig. 2). The most important building blocks are derived from acetyl-CoA, shikimic acid, mevalonic acid and deoxyxylulose. Some of the important classes of secondary metabolites derived from these pathways include: the anthraquinones from the acetate pathway; the alkaloids and phenylpropanoids (e.g. lignans, aromatic essential oils, and coumarins) from the shikimate pathway; a vast array of terpenoids and steroid metabolites, which include the saponins, terpenoid essential oils and carotenoids, derived from the mevalonate and deoxyxylulose pathways. Other building blocks based on amino acids are also frequently employed.

From this very modest number of building blocks a vast array of secondary compounds is synthesised. This range is achieved by for example combining building blocks of the same type, using mixtures of different building blocks (e.g. flavonoids are formed from combinations between the acetate and shikimate pathways) and incorporating one or more sugar units (e.g. saponins; Dewick, 2002). NAPRALERT, which is a database of the world literature of natural products, lists over 135000 isolated and characterised natural products (Cordell, 2000), which is probably just a small percentage if it is considered that only an estimated 5-15\% (Cragg et al. 1997) of the terrestrial species of plants have been investigated for the presence of secondary metabolites.

It has been suggested that this immense diversity of secondary metabolites has evolved to promote plant survival, as it ensures effectiveness against a wide range of herbivores and pathogens and decreases the chance of herbivores and pathogens developing resistance or adaptive responses (Briskin, 2000). Indeed, many of the beneficial actions of plant extracts are thought to be via the additive and/or synergistic actions of several secondary metabolites acting at single or multiple target sites. This complexity in terms of the number and the variability of secondary metabolites in plants, and the interactions between them, is a major limitation to the rate of progress that is being made in this area of research, where raw plant materials and plant extract preparations are being studied (Cordell, 2000).

\section{Manipulation of rumen metabolism}

Ruminant animals produce a high proportion of the quality dietary protein consumed by human populations throughout the world. In the EU approximately $25 \%$ of the meat (European Commission, 2001) and all the milk consumed (FAOSTAT, 2001) is of ruminant origin. The value of ruminant animals lies in their ability to utilise low-quality feeds, upgrading low-quality inputs to high-quality outputs. This ability is due to the symbiotic relationship between ruminants and the large microbial population within their rumen. The rumen microbial population is able to digest and ferment plant cell-wall polymers (cellulose, hemicellulose and pectin). Associated with this process is the production of volatile fatty acids, the major energy source in ruminants, accounting for approximately $80 \%$ of the energy disappearing from the rumen (France \& Siddons, 1993). In addition, the outflow of microbes from the rumen to the lower digestive tract accounts for a large percentage (50-75) of the protein digested in, and absorbed from, the small intestine (Agriculture and Food Research Council, 1992). Thus, the efficiency of rumen metabolism can have a profound effect on the production efficiency of the animal. The efficiency of rumen metabolism is also an important factor influencing the output of environment-polluting waste products. Inefficient $\mathrm{N}$ retention by rumen micro- 


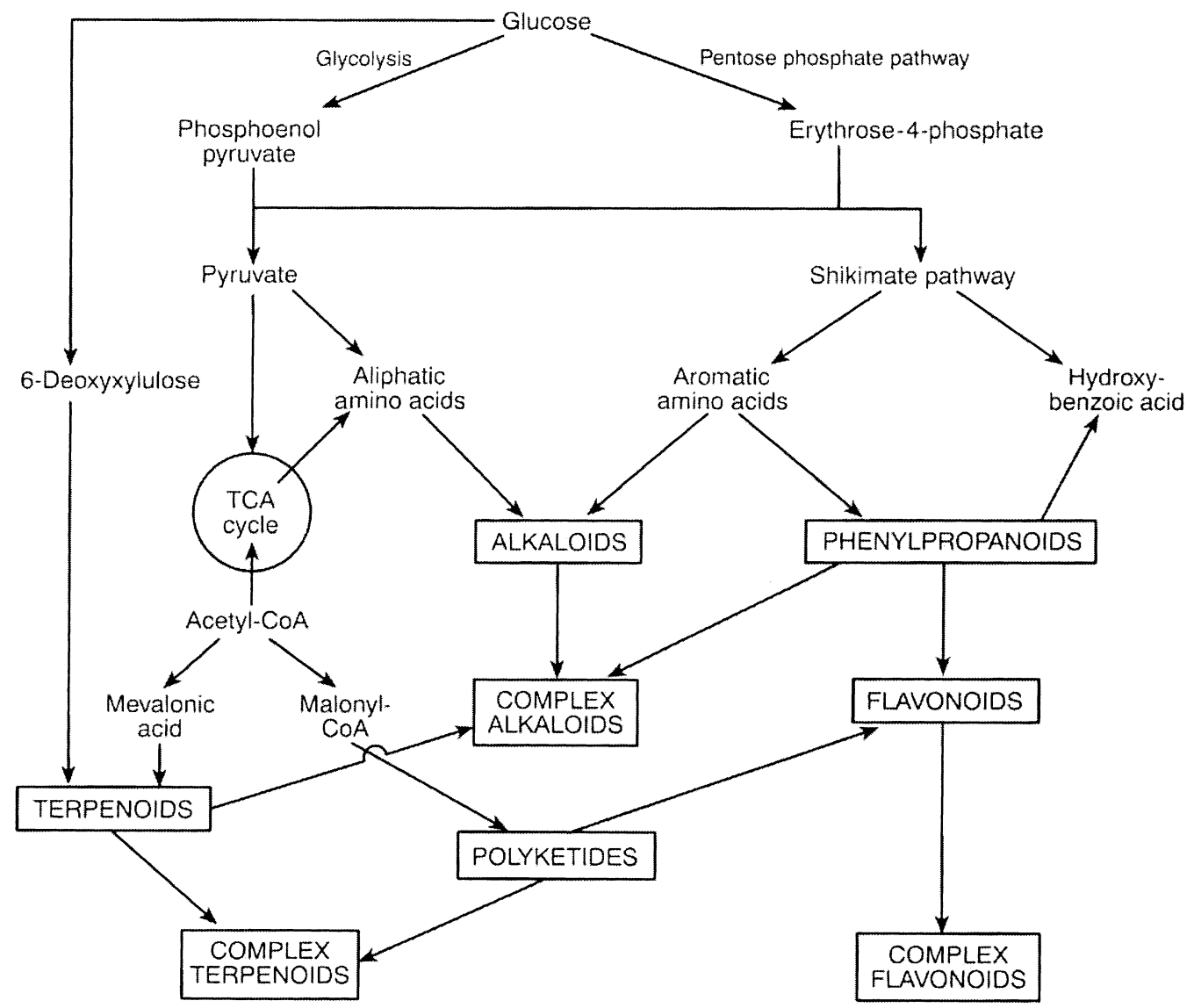

Fig. 2. Overview of plant secondary metabolism showing the interrelationships between the different pathways. TCA, tricarboxylic acid. (From Edwards \& Gatehouse, 1999.)

organisms leads to the excretion of N-rich wastes. Efficient rumen fermentation results in reduced methane production and emission. As a consequence there is considerable interest in the manipulation of rumen metabolism.

Probably the most extensively researched and reviewed of the plant secondary metabolites in terms of both their anti-nutritional and potential beneficial effects on ruminants are the tannins (polyphenolics; Aerts et al. 1999; Butter et al. 1999; McSweeney et al. 2001). Thus, tannins will not be considered here. Instead, the potential of essential oils as manipulators of rumen metabolism will be considered.

\section{Rumen bacteria}

Essential oils are complex mixtures of secondary metabolites consisting of low-boiling-point phenylpropenes (derived from the shikimate pathway) and terpenes (derived from the mevalonate and deoxyxyluose pathways). They are particularly associated with plants defined as herbs and spices', and are responsible for the characteristic essences and fragrances, the quinta essentia, of these plants. They are typically extracted from plants by distillation methods, in particular steam distillation. An example of some essential oils and their major components are presented in Table 1.

Many essential oils have dose-dependent bacteriocidal and bacteriostatic effects on micro-organisms (bacteria, fungi, viruses and protozoa; Smith-Palmer et al. 1998; Davidson \& Naidu, 2000). It has been reported that of the essential oil derivatives examined $60 \%$ are inhibitory to fungi and 30\% are inhibitory to bacteria (Cowan, 1999). These properties have understandably received much interest from both the food and pharmaceutical industries. In order to be able to exploit these properties for the manipulation of rumen fermentation it is necessary that the activity of essential oils be 'selective' against micro-organisms. There is good evidence to suggest that this is indeed the case for some essential oils, with specificity against bacteria being determined by the Gram-reaction.

Chao et al. (2000) investigated the inhibitory effects of forty-five essential oils on a broad spectrum of microorganisms, which included eight different genera of bacteria, four of which were Gram-positive (Bacillus cereus, Micrococcus luteus, Staphylococcus aureus, Streptococcus faecalis) and four of which were Gramnegative (Alcaligenes faecalis, Enterobacter cloacae, Escherichia coli, Pseudomonas aeruginosa). They concluded that Gram-negative bacteria were more resistant to the essential oils tested than the Gram-positive bacteria (Table 2). While some of the essential oils tested, i.e. the oils from cinnamon (Cinnamomum zeylanicum Blu) bark, savory (Satureja Montana L.) and rosewood (Aniba rosaeodora Ducke), were effective against both the 
Table 1. Some essential oils and their major components (Chao et al. 2000)

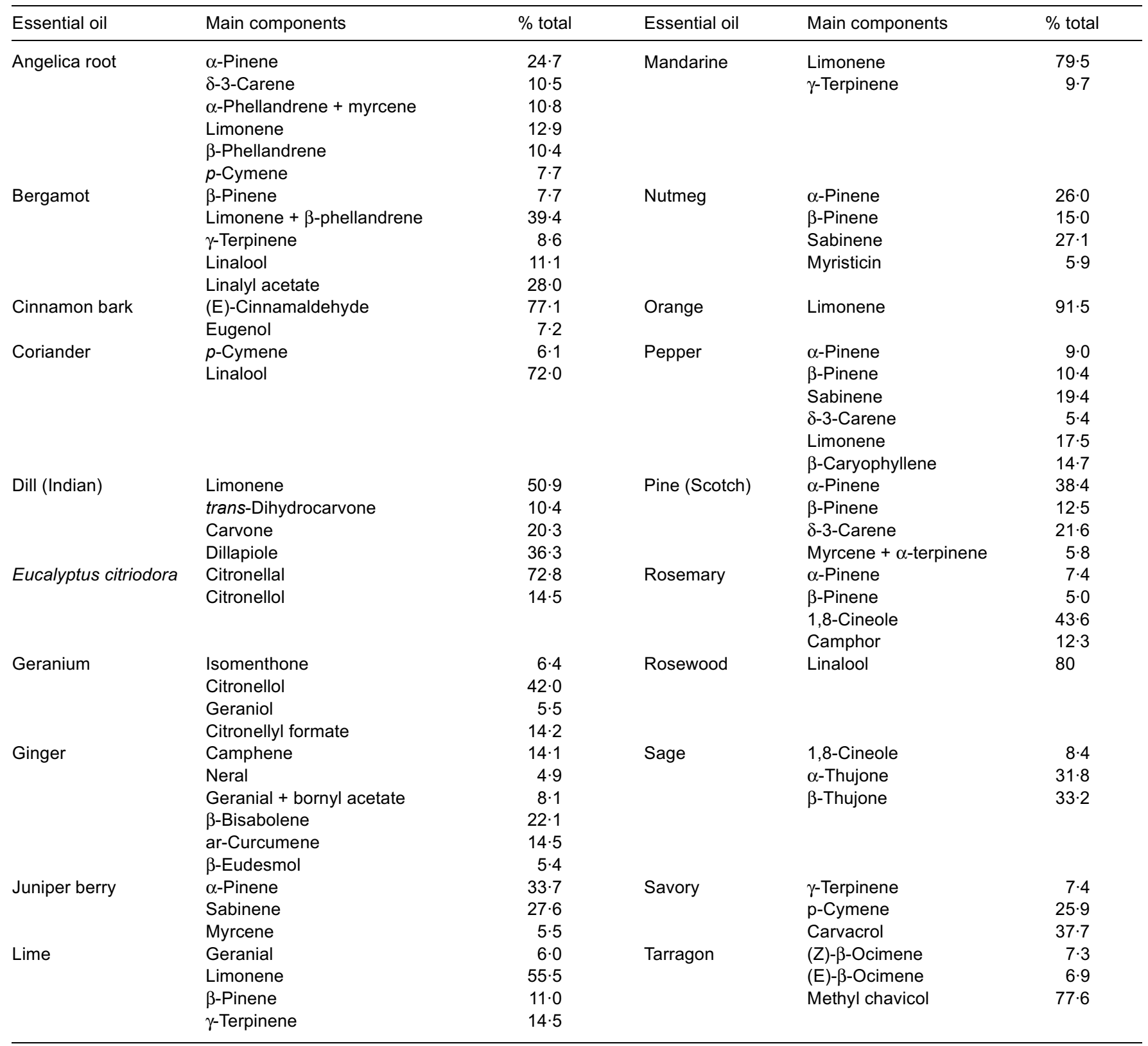

Gram-positive and Gram-negative bacteria, coriander (Coriandrum sativum L.) essential oil only inhibited the Gram-positive bacteria.

Smith-Palmer et al. (1998) investigated the effects of twenty-one essential oils on five food-borne pathogens, three of which were Gram-negative (E. coli, Salmonella enteritidis, Campylobacter jejuni) and two Gram-positive (S. aureus, Listeria monocytogenes). The bacteriostatic and bacteriocidal concentrations of the four most-inhibitory essential oils, i.e. bay (Laurus nobilis), cinnamon, clove (Syzygium aromaticum L.) and thyme (Thymus vulgaris L.), were generally lower for the Gram-positive bacteria than for the Gram-negative bacteria. It was concluded that Grampositive bacteria were more sensitive to inhibition by essential oils than Gram-negative bacteria. Similar observations and conclusions have been reported (Kivanc \& Akgul, 1986; Kubo et al. 1991; Kim et al. 1995; Mazzanti et al. 1998; Marino et al. 1999; Cox et al. 2000; Del Campo et al. 2000; Dorman \& Deans, 2000).

A number of mechanisms by which essential oils exert their antimicrobial activity have been postulated. For example, the antimicrobial activity of isothiocyanates derived from onion (Allium cepa) and garlic (Allium sativum) is thought to be due to their ability to inactivate extracellular enzymes (Brul \& Coote, 1999). However, the mechanism by which most essential oils are thought to exert their antibacterial effects is by disrupting cell wall structures. This activity affects electron transport, ion gradients, 
Table 2. Effect of essential oils on the growth inhibition of bacteria (adapted from Chao et al. 2000)

\begin{tabular}{|c|c|c|c|c|c|c|c|c|}
\hline \multirow[b]{3}{*}{ Essential oil } & \multicolumn{8}{|c|}{ Zone of inhibition (mm) } \\
\hline & \multicolumn{4}{|c|}{ Gram-positive bacteria } & \multicolumn{4}{|c|}{ Gram-negative bacteria } \\
\hline & $\mathrm{Bc}$ & MI & $\mathrm{Sa}$ & Ef & Ec & Af & $\mathrm{Ecl}$ & $\mathrm{Pa}$ \\
\hline Angelica & 2 & 4 & 4 & 4 & 2 & 7 & 1 & - \\
\hline Bergamot & 4 & 6 & 2 & 4 & 2 & 3 & 1 & - \\
\hline Cinnamon (bark) & 17 & 27 & 9 & 12 & 12 & 24 & 18 & 6 \\
\hline Coriander & $>33$ & $>33$ & 25 & $>33$ & - & 10 & - & - \\
\hline Dill (Indian) & 4 & 4 & 5 & 3 & 4 & 7 & 1 & 1 \\
\hline Eucalyptus citriodora & $>33$ & 4 & - & - & 1 & 7 & 2 & - \\
\hline Ginger & 2 & 2 & - & 1 & - & - & - & - \\
\hline Juniperberry & 4 & 7 & 3 & 2 & 2 & 10 & 1 & - \\
\hline Lime & 4 & 2 & 2 & 2 & - & 7 & - & 1 \\
\hline Mandarine & 3 & - & 4 & 4 & 1 & 6 & - & - \\
\hline Savory & 15 & $>33$ & 10 & 15 & 18 & 30 & 17 & - \\
\hline Nutmeg & 2 & 2 & 2 & 1 & 5 & 5 & 3 & - \\
\hline Orange & - & 3 & - & 2 & 1 & 5 & - & - \\
\hline Pepper & 1 & 2 & - & - & - & 8 & - & - \\
\hline Pine (Scotch) & 5 & 5 & 3 & 4 & 3 & 14 & - & - \\
\hline Rosemary & 3 & 2 & - & - & 6 & 6 & 3 & - \\
\hline Rosewood & 13 & 17 & 7 & 5 & 12 & 19 & 15 & - \\
\hline Sage & 2 & 4 & 2 & 1 & 2 & 12 & 2 & - \\
\hline Tarragon & 4 & 6 & 6 & 7 & 3 & 12 & 1 & - \\
\hline
\end{tabular}

Bc, Bacillus cereus; MI, Micrococcus luteus; Sa, Staphylococcus aureus; Ef, Streptococcus faecalis; Ec, Enterobacter cloacae; Af, Alcaligenes faecalis; Ecl, Escherichia coli; Pa, Pseudomonas aeruginosa.

protein translocation, phosphorylation steps and other enzyme-dependent reactions, causing the affected bacteria to lose chemi-osmotic control (Ultee et al. 1999; Cox et al. 2000; Dorman \& Deans, 2000). For example, Helander et al. (1998) reported that carvacrol and thymol, both of which were shown to inhibit the growth of $E$. coli, decreased the intracellular ATP concentration of $E$. coli, while simultaneously increasing the extracellular ATP concentration. Ultee et al. (1999), on the other hand, were unable to detect an increase in extracellular ATP concentration associated with the decrease in intracellular ATP concentration caused by the treatment of Bacillus cereus with carvacrol. They concluded that the depletion of the intracellular pool was not due to increased cell-wall permeability for ATP, but rather due to either a reduced rate of ATP synthesis or an increased rate of ATP hydrolysis. However, they did report that carvacrol increased cell-wall permeability for $\mathrm{H}^{+}$and $\mathrm{K}^{+}$.

It is the lipophilic character of essential oils that enables them to disrupt cell walls, as they consequently accumulate in membranes. Dorman \& Deans (2000) suggest the cellwall-disrupting activity of essential oils is a function of the lipophilic properties of the constituent secondary metabolites, the potency of their functional groups and their aqueous solubility. Gram-negative bacteria possess an outer membrane that contains lipopolysaccharide, which makes it a hydrophilic surface (Helander et al. 1998). It is, therefore, a permeability barrier to hydrophobic substances such as essential oils. This property would explain the resistance of Gram-negative bacteria to the antibacterial effects of some essential oils (Chao et al. 2000).

From the point of view of the manipulation of rumen metabolism, antimicrobial specificity based on the Gram-reaction could be useful. There are a myriad factors that will influence the bacterial-modulating properties of essential oils in the dynamic environment of the rumen, such as the effect of other feed components (Del Campo et al. 2000) and the various strains of bacteria present. It is interesting, therefore, to speculate on the possibilities of invoking a similar response in rumen metabolism and animal performance through the use of essential oils. Carboxylic polyether ionophore antibiotics such as monensin and lasalocid can be used to elicit this type of response. Ionophores, via their disruptive effects on membrane physiology, select against the Gram-positive bacteria in the rumen, stimulating propionate fermentations and reducing methane production amongst other effects (Bergen \& Bates, 1984). The net effect of feeding ionophores is improved efficiency of production.

Very little work has been published to date on the effects of essential oils on rumen micro-organisms and rumen metabolism. Evans \& Martin (2000) investigated the effect of thymol in vitro on the fermentation of glucose by Streptococcus bovis and Selenomonas ruminatium, principal amylase- and lactate-producing rumen bacteria respectively (Stewart \& Bryant, 1988), and by a mixed population of rumen micro-organisms. Thymol inhibited lactate production, glucose uptake and the growth of S. bovis and S. ruminatium. In the mixed population thymol inhibited fermentation. As thymol is active against both Gram-positive and Gramnegative bacteria this result is perhaps not surprising. Similar research using 'selective' essential oils is urgently required to determine the feasibility of using them to manipulate rumen metabolism.

Some essential oils have been reported to inhibit enzyme activity (Miyazawa et al. 1998; Roth et al. 1998; Perry et al. 2000). Thymol has been reported to be a strong deaminase inhibitor (Van Nevel \& Demeyer, 1988). Inhibition of 
specific enzymes, in particular those enzymes associated with proteolysis and deamination, could be useful in limiting rumen ammonia concentrations in animals fed fresh forages, as this action could potentially lead to more efficient utilisation of dietary $\mathrm{N}$.

Some herbs and spices and their extracts have been shown to stimulate the growth of certain bacteria, i.e. to have a prebiotic-type effect. A mixed spice treatment containing amongst other components garlic, nutmeg (Myristica fragrans Houtt.) and coriander has been shown to increase the growth of Lactobacillus plantarum and enhance their ability to ferment glucose (Nes \& Skjelkvale, 1982). Similarly, while oregano (Origanum vulgare) inhibits the growth of, and acid production by, L. plantarum and Pediococcus cerevisiae, the residues remaining after solvent extraction of oregano have been shown to increase acid production by these bacteria (Zaika \& Kissinger, 1981). It was concluded that oregano contains both an inhibitory and a stimulatory component, and that the inhibitory component was associated with the essential oil fraction, probably carvacrol and thymol, which was removed by solvent extraction. The prebiotic effects of herbs and spices and their extracts on rumen microflora in the rumen environment have not been investigated. Plants and their extracts with 'specific' prebiotic properties could be used to manipulate rumen metabolism; for example, to promote the growth of Gram-negative bacterial populations, or fibre-digesting bacterial populations.

\section{Rumen protozoa}

The rumen protozoa are proteolytic and actively ingest rumen bacteria. They are considered to be the most important cause of bacterial protein turnover in the rumen and, therefore, can have a major effect on the efficiency of rumen $\mathrm{N}$ metabolism (Wallace \& McPherson, 1987). There is, therefore, considerable interest in trying to improve the efficiency of $\mathrm{N}$ metabolism through manipulation of the rumen microfauna. Attempts to improve the efficiency through defaunation have resulted in inconsistent effects on animal performance, despite improvements in non- $\mathrm{NH}_{3}-\mathrm{N}$ flow to the duodenum (Jouany, 1996). This inconsistency could be attributed to the important contributions made by the rumen protozoa to the digestion of fibre and the maintenance of a stable rumen $\mathrm{pH}$. Partial defaunation or suppression of the rumen protozoa may prove to be consistently more beneficial to overall animal performance. The improvements in live-weight gain (Leng et al. 1992; Navas-Carnach et al. 1993) and wool growth (Leng et al. 1992) of sheep fed saponin-containing plants are probably attributable to the suppression of protozoan populations in the rumen by the saponins (Lu \& Jorgensen, 1987; Newbold et al. 1997; Teferedegne et al. 1999). Some essential oils have antiprotozoal activities; for example, artemisinin, a component of the essential oil extracted from sweet wormwood (Artemisia annua), has anti-malarial activity (Klayman, 1985), is suppressive towards the development of Cryptosporidium parvum in mice (Youn \& Noh, 2001) and is effective against some coccidian species in poultry (Allen et al. 1997). Such antiprotozoal activity could be exploited for the benefit of rumen $\mathrm{N}$ metabolism.

\section{Manipulation of peripheral metabolism}

Many plant secondary metabolites possess hormone-like bioactive properties. Most data on their systemic effects come from medical and pharmaceutical research. Very little research, if any at all, has investigated the possibilities of exploiting these properties to manipulate peripheral metabolism for the benefit of animal performance.

An important factor when considering the exploitation of plant secondary metabolites for the manipulation of peripheral metabolism is bioavailability. Bioavailability is dependent on the plant secondary metabolite(s) entering the systemic circulation intact after consumption following passage through the gut, across the gut wall and first passage through the liver (Wiseman, 1999). The gut, gut wall and liver can all extensively metabolise plant secondary metabolites before they reach the systemic circulation. For example, approximately $37 \%$ of the intake of capsaicin, the powerful and pungent phenylalanine-derived alkaloid in chilli peppers (Capsicum anuum), is metabolised in the lumen of the gut, approximately $80 \%$ is metabolised as it passes across the gut wall and $>95 \%$ is metabolised as it passes through the liver (Donnerer et al. 1990).

\section{Phyto-oestrogens}

In animal production phyto-oestrogens are probably the most well-known group of plant secondary metabolites that exhibit hormone-like activity. It was $>60$ years ago that the disruption of reproductive processes was linked to the consumption of Trifolium species of fodder crop, such as lucerne and clovers (Evans et al. 1941; Bennets et al. 1946). These important fodder crops were found to contain secondary metabolites that displayed oestrogenic activity, enabling them to interfere with normal reproductive processes. Today, $>300$ plants have been identified that possess compounds with oestrogenic activity (Mazur, 1998). Despite their effect on reproductive processes, it is their role in the prevention of major diseases, including heart disease and cancer, which has stimulated most research interest.

The oestrogenic plant secondary metabolites include the isoflavanoids such as daidzein (isoflavone), genistein (isoflavone) and coumestrol (coumestan) and the non-phytooestrogenic lignans secoisolariciresinol and matairesinol (Fig. 3). The isoflavanoids genistein and daidzein can occur in the free form and as glycosides. These molecules mimic the shape and polarity of the steroid hormone oestradiol and are able to bind to the oestrogen receptor, although their activity is less than that of oestradiol. In some tissues they can stimulate an oestrogenic response, whilst in other tissues they can antagonise the effect of oestrogens (Dewick, 2002).

Following ingestion, hydrolysis of the isoflavone conjugates by bacterial ß-glucuronidases is thought to be necessary before absorption can take place (Wiseman, 1999). The aglycones genistein and daidzein can be further metabolised by the gut bacteria. Daidzein can be metabolised to form either equol, which is oestrogenic, or $o$-desmethylangolensin, which is not oestrogenic. Genistein is metabolised to $p$-ethylphenol, which is not oestrogenic. It is thought that the bioavailabilities of genistein and daidzein are similar. The 
<smiles>CCOCCc1cc(O)ccc1C1CC[C@@]2(C)[C@@H](O)CC[C@H]2[C@H]1C</smiles>

Oestradiol<smiles>[R]c1cc(O)[c-]c2occ(-c3ccc(O)cc3)c(=O)c12</smiles>

$\mathrm{RH}$, daidzein

$\mathrm{ROH}$, genistein<smiles>CCOCCO</smiles>

Enterodiol<smiles>CCOC(=O)c1cccc(CC2C(=O)OC[C@H]2Cc2cccc(O)c2)c1</smiles><smiles>O=c1oc2cc(O)ccc2c2oc3cc(O)ccc3c12</smiles>

Coumestrol

Fig. 3. The structures of the steroid hormone oestradiol and selected phyto-oestrogens. (From Dewick, 2002.)

plant lignans matairesinol and secisolariciresinol are converted in the gut by bacteria to the phyto-oestrogens enterolactone and enterodiol respectively. The fact that both the isoflavones and lignans are metabolised by the gut bacteria does mean that their bioavailabilities could vary considerably between individuals.

From the point of view of non-reproductive animal performance, natural oestrogens (17ß-oestradiol and oestrone) and synthetic non-steroidal oestrogenic compounds (e.g. hexoestrol and zeranol) can, and are used to, elicit growth responses and changes in carcass composition in animals (Schmidely, 1993). For example, in castrate male ruminants oestrogens generally increase lean tissue deposition and decrease subcutaneous and intramuscular fat. Do phytooestrogens have a role to play in the control of animal growth and carcass composition, and if so, could plants and their extracts be exploited for this purpose?

\section{Phytosterols}

Another group of plant secondary metabolites that would be expected to have hormone-like effects in animals are the phytosterols, the most abundant of which are campesterol, sitosterol and stigmasterol. These compounds are very similar in structure to the mammalian steroids. In fact, sitosterol and stigmasterol are produced commercially from soyabeans as raw materials for the semi-synthesis of medicinal steroids. It has been suggested that plant-specific steroids may function as precursors for the animal steroids (Geuns, 1978). However, to date there is no evidence that phytosterols can be converted into endogenous cholesterol and related sterol hormones in vertebrates (Ling \& Jones, 1995), or that they have any oestrogenic effects in vivo or in vitro (Awad \& Fink, 2000). Furthermore, phytosterols have poor bioavailability. The absorption rate of phytosterols from the gastrointestinal tract is usually $<5 \%$ of the dietary levels (Ling \& Jones, 1995).

\section{Insulin-like and insulin-releasing plant secondary metabolites}

Before the discovery of insulin, plant remedies were widely used to treat diabetes mellitus, and still are by some individuals. More than 400 plants (Gray \& Flatt, 1999), and $>200$ individual plant secondary metabolites (Broadhurst et al. 2000) have been documented as being hypoglycaemic, due to pancreatic and/or extra-pancreatic activity; some of these plants are listed in Table 3. Imparl-Radosevich et al. (1998) reported that extracts from cinnamon improved insulin receptor function by activating 
insulin receptor kinase and inhibiting insulin receptor phosphates, leading to increased insulin sensitivity. By a combination of in vitro and in vivo experiments extracts from coriander (Coriandrum sativum), elder (Sambucus nigra), lucerne and agrimony (Agrimony eupatoria) have been shown to stimulate insulin secretion, enhance the uptake and metabolism of glucose by muscle and stimulate glycogenesis (Gray \& Flatt, 1997, 1998, 1999; Gray et al. 2000).

Insulin is a key anabolic hormone in the homoeostatic regulation of nutrient partitioning (Bauman, 1984). Thus, it would be interesting to know what effects, if any, plant secondary metabolites with insulin-like and insulinreleasing activity have on fat and protein metabolism. There are very few reports in the literature in which such activity has been investigated. Extracts from the seeds of bitter melon (Momordica charantia) have been shown to have anti-lipolytic and lipogenic effects in isolated rat adipocytes (Wong et al. 1985; Ng et al. 1986).

\section{Catecholamine analogues}

One of the oldest known drugs is ephedrine, which has been used by the Chinese to treat asthmatic and bronchial conditions for at least 5000 years. Ephedrine, a phenylalanine-derived alkaloid, is the main alkaloid in species of Ephedra, including E. sinica and E. equisetina from China and E. geriardiana, E. intermedia and E. major from India and Pakistan (Dewick, 2002). It is a structural analogue of the catecholamines adrenaline and noradrenaline (Fig. 4), and has similar actions to noradrenaline, causing elevation of blood pressure and inotropic and chronotropic actions in the heart (Newman et al. 2000). It is orally active and is thought to act indirectly on adrenoreceptors by displacing noradrenaline from storage vesicles in the nerve terminals (Newman et al. 2000).

The anti-asthmatic B-agonists salbutamol and salmetrol were modelled on ephedrine (Cragg et al. 1997). The repartitioning effects of $\beta$-agonists on nutrient utilisation are well documented, and in some countries they are licensed for use in animal production. In general, they increase the rate of weight gain, improve feed conversion efficiency, decrease carcass fat content (resulting in leaner carcasses) and increase dressing percentage (Moody et al. 2000). It would be interesting to know whether plant secondary metabolites with catecholamine-like bioactive properties could be exploited to provide the same benefits as $\beta$ agonists.

\section{Delivery of bioactive plants and their extracts to animals}

In order to fully exploit the bioactive properties of plants and their extracts for the benefit of animal performance serious consideration needs to be given to methods of delivery. Arguably the extent to which plants and their extracts can be exploited is dependent on the extent to which dosage can be controlled, and this factor is dependent on the method of delivery. However, dosage is dependent on knowing the chemical and/or biological (i.e. bioactivity) character of the plant preparation being used. This information is often unavailable or limited, usually because of the complex array of secondary metabolites found in plants and their extracts, and the often complex interactions between them, as discussed earlier. For example, no such information is available where fresh plant materials have been used. Where dried plant and plant extract preparations

Table 3. Some hypoglycaemic plants and their suggested mechanisms of action

\begin{tabular}{|c|c|c|c|}
\hline Common name & Botanical name & Action & Reference \\
\hline Cinnamon & Cinnamomum spp. & Improved insulin receptor function & Imparl-Radosevich et al. (1998) \\
\hline Cardo santo & Cirsium pascuarense & Stimulated insulin secretion & Perez et al. (2001) \\
\hline Coriander & Coriandrum sativum | & Stimulated insulin secretion; enhanced uptake and & Gray \& Flatt (1999) \\
\hline Elder & Sambucus nigra & metabolism of glucose by muscle; & Gray et al. (2000) \\
\hline Lucerne & Medicago sativa & stimulated glycogenesis & Gray \& Flatt (1997) \\
\hline Agrimony & Agrimony eupatoria & & Gray \& Flatt (1998) \\
\hline Ezovian & Teucrium polium & $\begin{array}{l}\text { Increased peripheral metabolism of glucose; } \\
\text { stimulated insulin secretion }\end{array}$ & Gharaibeh et al. (1988) \\
\hline Spider flower & Cleome droserifolia & $\begin{array}{l}\text { Potentiation of hepatic and peripheral insulin sensi- } \\
\text { tivity; reduced glucose absorption }\end{array}$ & Wang \& Ng (1999) \\
\hline
\end{tabular}

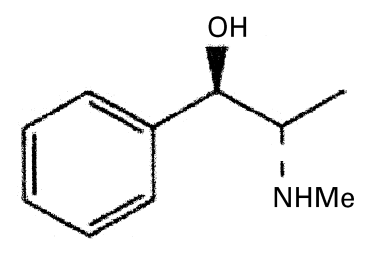

(-)-Ephedrine<smiles>CNC[C@H](O)c1ccc(O)c(O)c1</smiles>

Adrenaline<smiles>NC[C@@H](O)c1ccc(O)c(O)c1</smiles>

Noradrenaline

Fig. 4. Ephedrine, a structural analogue of the catecholamines adrenaline and noradrenaline. (From Dewick, 2002.) 
have been used information on biological activity should be known; however, due to the complex chemical composition of such preparations, chemical character is very rarely known (Cordell, 2000). The most-well-characterised preparations are those based on single purified plant secondary metabolites or mixtures of these compounds.

Methods have been developed in order to try to establish the character of complex mixtures of secondary metabolites. Often a single active or marker compound is assayed. For example, hypericin is used as a marker in St John's wort (Hypericum perforatum) products. Another method used is the preparation of a qualitative and quantitative profile of all the 'significant' constituents. Profiles of mixtures can then be compared. This method is known as phytoequivalence (Tyler, 1999). However, both methods are inadequate. The identity of all the active constituents is often unknown and they do not take account of the possible interactions between the assayed compounds and the non-assayed compounds.

Arguably the simplest method of delivering bioactive plant secondary metabolites to animals outdoors would be to grow the relevant plants in a field and then let the animals graze them in a controlled manner, assuming they are palatable. However, the efficacy of such a method is doubtful, since despite the crude control of intake via controlled grazing, there would be no control on dosage due to the inter-plant variability in secondary metabolites content, as discussed earlier. Methods of uniformly stressing crops to ensure a uniformity of secondary metabolite production, and perhaps even invoking the production of specific secondary metabolites, should be investigated.

Currently, the only way to ensure controlled dosage is to use characterised dried plant material, plant extracts or isolated bioactive secondary metabolite(s). These sources could be incorporated as 'natural' additives into supplemental concentrate feeds. In the case of plant extracts and isolated bioactive secondary metabolites alternative ways of delivery might include lick blocks, and in the case of ruminants rumen boluses. The latter method is considered to have good potential for the delivery of bioactive plant secondary metabolites to animals in a controlled manner, and in particular to animals reared extensively.

\section{Conclusions}

Due to circumstance, the EU is in a good position to establish itself as an international scientific leader in the use of plants and their extracts as alternative performance enhancers for animals. A number of possibilities for the exploitation of bioactive plant secondary metabolites for the improvement of animal productivity have been discussed, particularly in relation to rumen and peripheral metabolism. A challenge for the scientific community and the animal industry is to ensure that claims made for plants and their extracts are justified by sound and reliable data. This field of research should prove to be not only of strategic and applied interest, but also of fundamental interest, since it will contribute to our knowledge of the interactions between animals and the 'cocktail' of phytochemicals they consume every day, and their outcomes.

\section{References}

Aerts RJ, Barry TN \& McNabb WC (1999) Polyphenols and agriculture: beneficial effects of proanthocyanidins in forages. Agriculture Ecosystems and Environment 75, 1-12.

Agriculture and Food Research Council (1992) Nutritive requirements of ruminant animals: protein. Nutrition Abstract Reviews 62B, 787-835.

Allen PC, Lydon J \& Danforth HD (1997) Effects of components of Artemisia annua on coccidia infections in chickens. Poultry Science 76, 1156-1163.

Awad AB \& Fink CS (2000) Phytosterols as anticancer dietary components: evidence and mechanism of action. Journal of Nutrition 130, 2127-2130.

Bauman DE (1984) Regulation of nutrient partitioning. In Herbivore Nutrition in the Subtropics and Tropics, pp. 505-524 [FMC Gilchrist and RI Mackie, editors]. Craighall, South Africa: Science Press.

Bennets HW, Underwood EJ \& Shier FL (1946) A specific breeding problem of sheep on subterranean clover pastures in Western Australia. Australian Veterinary Journal 22, 2-12.

Bergen WG \& Bates DB (1984) Ionophores - their effect on production efficiency and mode of action. Journal of Animal Science 58, 1465-1483.

Briskin DP (2000) Medicinal plants and phytomedicines. Linking plant biochemistry and physiology to human health. Plant Physiology 124, 507-514.

Broadhurst CL, Polansky MM \& Anderson RA (2000) Insulin-like biological activity of culinary and medicinal plant aqueous extracts in vitro. Journal of Agricultural and Food Chemistry 48, 849-852.

Brul S \& Coote P (1999) Preservative agents in foods - mode of action and microbial resistance mechanisms. International Journal of Food Microbiology 50, 1-17.

Butter NL, Dawson JM \& Buttery PJ (1999) Effects of dietary tannins on ruminants. In Secondary Plant Products, pp. 51-70 [JC Caygill and I Meuller-Harvey, editors]. Nottingham: Nottingham University Press.

Chao SC, Young DG \& Oberg CJ (2000) Screening for inhibitory activity of essential oils on selected bacteria, fungi and viruses. Journal of Essential Oil Research 12, 639-649.

Cordell GA (2000) Biodiversity and drug discovery - a symbiotic relationship. Phytochemistry 55, 463-480.

Cowan MM (1999) Plant products as antimicrobial agents. Clinical Microbiology Reviews 12, 564-582.

Cox SD, Mann CM, Markham JL, Bell HC, Gustafson JE, Warmington JR \& Wyllie SG (2000) The mode of antimicrobial action of the essential oil of Melaleuca alternifolia (tea tree oil). Journal of Applied Microbiology 88, 170-175.

Cragg GM, Newman DJ \& Snader KM (1997) Natural products in drug discovery and development. Journal of Natural Products 60, 52-60.

Davidson PM \& Naidu AS (2000) Phyto-phenols. In Natural Food Antimicrobial Systems, pp. 265-294 [AS Naidu, editor]. Boca Raton, FL: CRC Press.

Del Campo J, Amiot MJ \& Nguyen-The C (2000) Antimicrobial effect of rosemary extracts. Journal of Food Protection 63, $1359-1368$.

Dewick PM (2002) Medicinal Natural Products, 2nd ed. Chichester, West Sussex: John Wiley \& Sons Ltd.

Donnerer J, Amann R, Schuligoi R \& Lembeck F (1990) Absorption and metabolism of capsaicinoids following intragastric administration in rats. Naunyn-Schmiedebergs Archives of Pharmacology 342, 357-361.

Dorman HJD \& Deans SG (2000) Antimicrobial agents from plants: antibacterial activity of plant volatile oils. Journal of Applied Microbiology 88, 308-316. 
Edwards R \& Gatehouse JA (1999) Secondary metabolism. In Plant Biochemistry and Molecular Biology, pp. 193-218 [PJ Lea and RC Leegood, editors]. Chichester, West Sussex: John Wiley $\&$ Sons Ltd.

European Commission (2001) Prospects for Agricultural Markets 2001-2008. http://europa.eu.int/comm/agriculture/publi/caprep/ prospects2001/index_en.htm

Evans JA, Varney RF \& Koch FC (1941) The mouse uterine weight method for the assay of estrogens. Endocrinology 28, 747.

Evans JD \& Martin SA (2000) Effects of thymol on ruminal microorganisms. Current Microbiology 41, 336-340.

Evans T, McDougall J \& Phillips M (1999) The Strategic Positioning of Major Medicinal Feed Additives Companies in Response to European Union Developments. Edinburgh: Wood Mackenzie.

FAOSTAT (2001) Agriculture Data: Food and Agricultural Organization of the United Nations. http://apps.fao.org/default.htm

Farnsworth NR, Akerele O, Bingel AS, Soejarto DD \& Guo Z (1985) Medicinal plants in therapy. Bulletin of the World Health Organization 63, 965-981.

France J \& Siddons RC (1993) Volatile fatty acid production. In Quantitative Aspects of Ruminant Digestion and Metabolism, pp. 107-121 [JM Forbes and J France, editors]. Wallingford, Oxon.: CAB International.

Frost \& Sullivan (2000) Strategic analysis and forecasts of the essential oils market for animal health feed additives. In European Animal Health Feed Additives Markets, pp. 10.1-10.12. Report no. 3876-42: www.frost.com

Geuns JMC (1978) Steroid hormones and plant growth and development. Phytochemistry 17, 1-14.

Gharaibeh MN, Elayan HH \& Salhab AS (1988) Hypoglycemic effects of Teucrium polium. Journal of Ethnopharmacology 24, 93-99.

Gottlieb OR (1990) Phytochemicals - differentiation and function. Phytochemistry 29, 1715-1724.

Gray AM, Abdel-Wahab YHA \& Flatt PR (2000) The traditional plant treatment, Sambucus nigra (elder), exhibits insulin-like and insulin-releasing actions in vitro. Journal of Nutrition 130, $15-20$.

Gray AM \& Flatt PR (1997) Pancreatic and extra-pancreatic effects of the traditional anti-diabetic plant, Medicago sativa (lucerne). British Journal of Nutrition 78, 325-334.

Gray AM \& Flatt PR (1998) Actions of the traditional anti-diabetic plant, Agrimony eupatoria (agrimony): effects on hyperglycaemia, cellular glucose metabolism and insulin secretion. British Journal of Nutrition 80, 109-114.

Gray AM \& Flatt PR (1999) Insulin-releasing and insulin-like activity of the traditional anti-diabetic plant Coriandrum sativum (coriander). British Journal of Nutrition 81, 203-209.

Helander IM, Alakomi HL, Latva-Kala K, Mattila-Sandholm T, Pol I, Smid EJ, Gorris LGM \& von Wright A (1998) Characterization of the action of selected essential oil components on Gramnegative bacteria. Journal of Agricultural and Food Chemistry 46, 3590-3595.

Imparl-Radosevich J, Deas S, Polansky MM, Baedke DA, Ingebritsen TS, Anderson RA \& Graves DJ (1998) Regulation of PTP-1 and insulin receptor kinase by fractions from cinnamon: implications for cinnamon regulation of insulin signalling. Hormone Research 50, 177-182.

Jouany JP (1996) Effect of rumen protozoa on nitrogen utilization by ruminants. Journal of Nutrition 126, S1335-S1346.

Kim JM, Marshall MR \& Wei C (1995) Antibacterial activity of some essential oil components against 5 foodborne pathogens. Journal of Agricultural and Food Chemistry 43, 2839-2845.
Kivanc M \& Akgul A (1986) Antibacterial activities of essential oils from Turkish spices and citrus. Flavour and Fragrance Journal 1, 175-179.

Klayman DL (1985) Qinghaosu (artemisinin) - an antimalarial drug from China. Science 228, 1049-1055.

Kubo I, Himejima M \& Muroi H (1991) Antimicrobial activity of flavor components of cardamom Elattaria cardamomum (Zingiberaceae) seed. Journal of Agricultural and Food Chemistry 39, 1984-1986.

Lawrence B \& Hahn H (2001) Swine feeding programs without antibiotics. 62nd Minnesota Nutrition Conference. http:// www.conferences.umn.edu/mn/livestok/2303/papers/022303/ Windows/PDFs/13_2B6.pdf

Leng RA, Bird SH, Klieve A, Choo BS, Ball FM, Asefa G, Brumby P, Mudgal VD, Chaudhry UB, Haryono SU \& Hendratno N (1992) The potential for tree forage supplements to manipulate rumen protozoa to enhance protein to energy ratios in ruminants fed on poor quality forages. In Legume Trees and other Fodder Trees as Protein Sources for Livestock, pp. 177-191 [A Speedy and PL Pugliese, editors]. Rome: FAO.

Ling WH \& Jones PJH (1995) Dietary phytosterols - a review of metabolism, benefits and side-effects. Life Sciences 57, 195-206.

Lu CD \& Jorgensen NA (1987) Alfalfa saponins affect site and extent of nutrient digestion in ruminants. Journal of Nutrition 117, 919-927.

McNaughton SJ, Tarrants JL, McNaughton MM \& Davis RH (1985) Silica as a defense against herbivory and a growth promotor in African grasses. Ecology 66, 528-535.

McSweeney CS, Palmer B, McNeill DM \& Krause DO (2001) Microbial interactions with tannins: nutritional consequences for ruminants. Animal Feed Science and Technology 91, 83-93.

Marino M, Bersani C \& Comi G (1999) Antimicrobial activity of the essential oils of Thymus vulgaris L. measured using a bioimpedometric method. Journal of Food Protection 62, 1017-1023.

Marriott BM (2000) Functional foods: an ecologic perspective. American Journal of Clinical Nutrition 71, 1728S-1734S.

Mazur W (1998) Phytoestrogen content in foods. Baillieres Clinical Endocrinology and Metabolism 12, 729-742.

Mazzanti G, Battinelli L \& Salvatore G (1998) Antimicrobial properties of the linalol-rich essential oil of Hyssopus officinalis $\mathrm{L}$. var decumbens (Lamiaceae). Flavour and Fragrance Journal 13, 289-294

Miyazawa M, Watanabe H, Umemoto K \& Kameoka H (1998) Inhibition of acetylcholinesterase activity by essential oils of Mentha species. Journal of Agricultural and Food Chemistry 46, 3431-3434.

Moody DE, Hancock DL \& Anderson DB (2000) Phenethanolamine repartitioning agents. In Farm Animal Metabolism and Nutrition, pp. 65-96 [JPF D'Mello, editor]. Wallingford, Oxon.: CABI Publishing.

Navas-Carnach A, Laredo MA, Cuesta A, Anzola H \& Leon JC (1993) Effect of supplementation with a tree legume forage on rumen function. Livestock Research for Rural Development $\mathbf{5}$, $58-71$.

Nes IF \& Skjelkvale R (1982) Effect of natural spices and oleoresins on Lactobacillus plantarum in the fermentation of dry sausage. Journal of Food Science 47, 1618-1625.

Newbold CJ, El Hassan SM, Wang J, Ortega ME \& Wallace RJ (1997) Influence of foliage from African multipurpose trees on activity of rumen protozoa and bacteria. British Journal of Nutrition 78, 237-249.

Newman DJ, Cragg GM \& Snader KM (2000) The influence of natural products upon drug discovery. Natural Product Reports 17, 215-234. 
Ng TB, Wong CM, Li WW \& Yeung HW (1986) Insulin-like molecules in Momordica charantia seeds. Journal of Ethnopharmacology 15, 107-117.

Perez RM, Ramirez E \& Vargas R (2001) Effect of Cirsium pascuarense on blood glucose levels of normoglycaemic and alloxan-diabetic mice. Phytotherapy Research 15, 552-554.

Perry NSL, Houghton PJ, Theobald A, Jenner P \& Perry EK (2000) In vitro inhibition of human erythrocyte acetylcholinesterase by Salvia lavandulaefolia essential oil and constituent terpenes. Journal of Pharmacy and Pharmacology 52, 895-902.

Roberfroid MB (1999) Concepts in functional foods: The case of inulin and oligofructose. Journal of Nutrition 129, 1398S-1401S.

Roth GN, Chandra A \& Nair MG (1998) Novel bioactivities of Curcuma longa constituents. Journal of Natural Products 61, 542-545.

Saucier L (1999) Meat safety: challenges for the future. Outlook on Agriculture 28, 77-82.

Schmidely P (1993) Quantitative review on the use of anabolic hormones with steroidal activity in ruminants reared for meat production. 2. Modes of action. Reproduction Nutrition Development 33, 297-323.

Shu YZ (1998) Recent natural products based drug development: a pharmaceutical industry perspective. Journal of Natural Products 61, 1053-1071.

Smith-Palmer A, Stewart J \& Fyfe L (1998) Antimicrobial properties of plant essential oils and essences against five important foodborne pathogens. Letters in Applied Microbiology 26, 118-122.

Stewart CS \& Bryant MP (1988) The rumen bacteria. In The Rumen Microbial Ecosystem, pp. 21-75 [PN Hobson, editor]. London and New York: Elsevier Applied Science.

Teferedegne B, McIntosh F, Osuji PO, Odenyo A, Wallace RJ \& Newbold CJ (1999) Influence of foliage from different accessions of the sub-tropical leguminous tree, Sesbania sesban, on ruminal protozoa in Ethiopian and Scottish sheep. Animal Feed Science and Technology 78, 11-20.

Tyler VE (1999) Phytomedicines: back to the future. Journal of Natural Products 62, 1589-1592.

Ultee A, Kets EPW \& Smid EJ (1999) Mechanisms of action of carvacrol on the food-borne pathogen Bacillus cereus. Applied and Environmental Microbiology 65, 4606-4610.

Van Nevel CJ \& Demeyer DI (1988) Manipulation of rumen fermentation. In The Rumen Microbial Ecosystem, pp. 387-443 [PN Hobson, editor]. London and New York: Elsevier Applied Science.

Wallace RJ \& McPherson CA (1987) Factors affecting the rate of breakdown of bacterial protein in rumen fluid. British Journal of Nutrition 58, 313-323.

Wang HX \& Ng TB (1999) Natural products with hypoglycemic, hypotensive, hypocholesterolemic, antiatherosclerotic and antithrombotic activities. Life Sciences $\mathbf{6 5}, 2663-2677$.

Wiseman H (1999) The bioavailability of non-nutrient plant factors: dietary flavonoids and phyto-oestrogens. Proceedings of the Nutrition Society 58, 139-146.

Wong CM, Ng TB \& Yeung HW (1985) Screening of Trichosanthes kirilowii, Momordica charantia and Cucurbita maxima (Family Cucurbitaceae) for compounds with antilipolytic activity. Journal of Ethnopharmacology 13, 313-321.

Youn HJ \& Noh JW (2001) Screening of the anticoccidial effects of herb extracts against Eimeria tenella. Veterinary Parasitology 96, 257-263.

Zaika LL \& Kissinger JC (1981) Inhibitory and stimulatory effects of oregano on Lactobacillus plantarum and Pediococcus cerevisiae. Journal of Food Science 46, 1205-1210. 